\title{
Innovative Development of Multimedia Technology and Visual Communication Design
}

\author{
Limin Fang \\ College of Technology and Art Jingdezhen Ceramic Institnte333001
}

Key words: multimedia technology; visual communication design teaching; innovation

\begin{abstract}
In the field of visual communication design, innovation is always an inexhaustible motive force for its ' long-term and stable development, and it is also in line with the mainstream trend of contemporary times and industrial development . In the face of the rapid development of multimedia

technology, innovative talents training in visual ${ }^{\top}$ communication ${ }^{\top}$ designs ${ }^{\top}$ teaching ${ }^{\top}$ work, It also must combine with the current development of the actual needs and technical characteristics, and establish a sense of innovation to meet the training needs of outstanding professionals . This paper briefly expounds the influence of multimedia technology on the teaching of visual communication design , and further puts forward some suggestions on the key of visual communication design teaching under the guidance of innovative ideas .
\end{abstract}

\section{Introduction}

With the continuous development of scientific and technological means, interpersonal communication has been a breakthrough time and space constraints, and also began to develop to visual from the direction of traditional sound, text and other forms. Based on the application of this multimedia technology, in the visual communication design teaching work, we need to introduce more innovative ideas, change the traditional teaching methods, with a view to achieving innovative development. At the same time the application of multimedia technology can also promote the design of education to achieve a higher more diversified and informationize level.

\section{Influence of Multimedia Technology on the Teaching of Visual Communication}

Through the application of multimedia technology in visual communication design teaching process, it can realize the innovative development of teaching methods and contents. Based on the teaching level, the use of multimedia technology can effectively promote the students ' thinking ability , observation ability, aesthetic ability, innovation ability and other aspects of comprehensive ability level to achieve a comprehensive development, also establish a more comprehensive and systematic diversified knowledge system through the professional knowledge of the process of learning . In contrast to the traditional teaching methods prevailing over the past, through the full application of multimedia technology, it will help to play the flexible characteristics of teaching methods, making the daily teaching work becomes flexible, through the more powerful creativity ability and a good intuitive feel to implement the relevant teaching tasks .

At the same time, considering the teaching resources, the application of multimedia technology can bring more diversified resource elements to the classroom teaching activities, break the negative impact restrictions, making the teaching method can be more effectively adapted to the current social development situation. The design of teaching objectives are proposed by the new requirements. The effective application of multimedia technology is a new way of visual media, which will be combined with a richer teaching content, so that the whole teaching work becomes more diverse, three-dimensional [1]. Through the application of multimedia technology in the daily course of teaching, but also to achieve the limitations of the limitations of textbooks, to promote the overall teaching process become more visualized, to enable students to more truly feel the knowledge of the content learned, it not only can promote the teaching quality of the substantial increase, which can make the teaching capacity significantly improved, students will also produce a 
greater interest in learning, and fully mobilize the students from the subjective initiative, so that students are more active in learning activities, this feature is also fit in today's era of quality education for students to pursue the pursuit of value.

\section{Visual Communication Design Teaching Based on Innovation Idea}

\subsection{Make Sure Students in Dominant Position}

In the new situation of social development today, no matter what kind of education work, students should always be in the main position, it is also true of/to visual communication designs teaching [2]. Although the current level of teaching and learning has paid more attention, but we still need to ensure that students are at the dominant position in the teaching process, which cannot shake. In the application of multimedia technology daily teaching work, to make real-time adjustments we must ensure that the teaching content, methods, strategies according to the actual situation, to join them in accordance with the overall ideological connotation of the thinking and teaching methods . Attach great importance of the student's main position, in carrying out the teaching design and even the specific aspects of the adjustment, we must do a good job to control the overall situation closely around the individual level of students and the ability, and we should not only apply the multimedia technology. Contemporary education in terms of personnel training, the work of innovation should be based on a number of different dimensions of the common progress, and also focus on the status of students to do a precise implementation, only to do this we can achieve the effective implementation of the development needs of innovation [3] .

\subsection{Establish Practical Teaching System}

In the new situation of social development today, no matter what kind of education work, students should always be in the main position, it is also true of visual communication designs teaching [2]. Although the current level of teaching and learning has paid more attention, but we still need to ensure that students are at the dominant position in the teaching process, which cannot shake. In the application of multimedia technology daily teaching work, to make real-time adjustments we must ensure that the teaching content, methods, strategies according to the actual situation, to join them in accordance with the overall ideological connotation of the thinking and teaching methods . Attach great importance of the student's main position, in carrying out the teaching design and even the specific aspects of the adjustment, we must do a good job to control the overall situation closely around the individual level of students and the ability, and we should not only apply the multimedia technology. Contemporary education in terms of personnel training, the work of innovation should be based on a number of different dimensions of the common progress, and also focus on the status of students to do a precise implementation, only to do this we can achieve the effective implementation of the development needs of innovation [3] .

From the school point of view, in the relevant teaching activities, should also focus on cultivation and enhancement of the comprehensive quality of students, to promote students to break the traditional way of learning constraints, to form a self consciousness, become the master of knowledge in the learning process, and also be able to achieve personal growth and overall development truly in the new teaching system. In the creation or adjustment of the relevant knowledge of the teaching system, the majority of educators should also enhance the students ' ability considering from a more long-term perspective to focus on the relevant social positions in the human capacity needs of students to carry out according to targeted professional training and ability, and at the same time integrated the exchange with its own distinctive characteristics into the teaching philosophy, and always adhere to the people-oriented concept of personnel training .In addition, teachers should actively change the traditional teaching ideas that have been clearly out of date, and realize the key value of the new technical means in the daily teaching work. Through the transformation of the traditional teaching idea and the combination of the actual teaching idea. More fully applied the teaching needs and experience in the multimedia technology to do the daily teaching practice, through the application of new technology to add interest to the classroom 
teaching, and provide good helps, promote effect on the daily teaching .

\subsection{Control Technology Application Scale}

For the visual communication design teaching activities, the innovative development of the majority of educators needs to continue to think and explore active. And in order to really to promote the daily teaching work to achieve the innovation and development, it will be crucial forth applications of a variety of multimedia technologies, but at the same time we should also focus on how to control the application of multimedia technology standards. Although the application of multimedia technology in daily teaching activities can be good to meet the diverse needs of teaching. However, if use the multimedia technology blindly, and can not determine the rationalization of multimedia technology application standards, the overall teaching effect will effected [5] .In the process of applying multimedia technology, we should avoid excessive correction, completely abandon the traditional teaching methods, but should do organic integration between modern teaching ideas and traditional teaching ideas, take the essence of each part to achieve the powerful combination $t$, only to do this can lead to visual communication design courses achieve a better quality of teaching. Under the influence of the sustainable development of multimedia technology, teachers themselves should be form an objective understanding in the ideological awareness of the application of multimedia technology, and actively participate in various teaching and training activities to promote themselves in the application of multimedia technology with better control, and achieve the rationalization of multimedia technology applications.

\section{Conclusion:}

All in all, visual communication designs work will also get more information resources and media elements effected by the ongoing development of digital information technology, and at the same time establish a new type of cultural relevance. In the process of carrying out the visual communication design teaching work, the relevant educators can carry on the deep excavation to the digital information resources, constantly complement and perfect the related course content, choose the more reasonable teaching way to enhance the teaching effect.

\section{References:}

[1] Wang Zhigang, Zang Zhiyun. Analysis of the influence of digital media on visual communication design [J]. Journal of Jiangsu Teachers College of Technology, 2014, (2).

[2] Wang Qi. Media technology and visual communication design teaching innovation development [J]. Science and Technology Information, 2016,14 (13).

[3] Sun Bo. Analysis of digital technology in the visual communication design of the application [J]. Art circles, 2013, (9).

[4] Wei Hualing. Visual interaction in visual communication design [J]. Yihai, 2013, (4).

[5] Tan Qian. Visual communication design theory and teaching research - Comment on "visual communication design" [J]. News and writing, 2016, (12). 